\title{
Investigation of Potent Lead for Acquired Immunodeficiency Syndrome from Traditional Chinese Medicine
}

\author{
Tzu-Chieh Hung, ${ }^{1}$ Wen-Yuan Lee, ${ }^{1,2,3}$ Kuen-Bao Chen, ${ }^{1,2,4}$ \\ Yueh-Chiu Chan, ${ }^{2}$ and Calvin Yu-Chian Chen ${ }^{1,2,5}$ \\ ${ }^{1}$ Department of Biomedical Informatics, Asia University, Taichung 41354, Taiwan \\ ${ }^{2}$ School of Medicine, College of Medicine, China Medical University, Taichung 40402, Taiwan \\ ${ }^{3}$ Department of Neurosurgery, China Medical University Hospital, No. 2, Yude Road, North District, Taichung City 40447, Taiwan \\ ${ }^{4}$ Department of Anesthesiology, China Medical University Hospital, Taichung 40447, Taiwan \\ ${ }^{5}$ Research Center for Chinese Medicine \& Acupuncture, China Medical University, Taichung 40402, Taiwan
}

Correspondence should be addressed to Calvin Yu-Chian Chen; ycc929@MIT.edu

Received 25 February 2014; Revised 5 March 2014; Accepted 5 March 2014; Published 12 June 2014

Academic Editor: Chung Y. Hsu

Copyright (C) 2014 Tzu-Chieh Hung et al. This is an open access article distributed under the Creative Commons Attribution License, which permits unrestricted use, distribution, and reproduction in any medium, provided the original work is properly cited.

\begin{abstract}
Acquired immunodeficiency syndrome (AIDS), caused by human immunodeficiency virus (HIV), has become, because of the rapid spread of the disease, a serious global problem and cannot be treated. Recent studies indicate that VIF is a protein of HIV to prevent all of human immunity to attack HIV. Molecular compounds of traditional Chinese medicine (TCM) database filtered through molecular docking and molecular dynamics simulations to inhibit VIF can protect against HIV. Glutamic acid, plantagoguanidinic acid, and Aurantiamide acetate based docking score higher with other TCM compounds selected. Molecular dynamics are useful for analysis and detection ligand interactions. According to the docking position, hydrophobic interactions, hydrogen bonding changes, and structure variation, the study try to select the efficacy of traditional Chinese medicine compound Aurantiamide acetate is better than the other for protein-ligand interactions to maintain the protein composition, based on changes in the structure.
\end{abstract}

\section{Introduction}

Human immunodeficiency virus (HIV) is a retrovirus that causes acquired immunodeficiency syndrome (AIDS) [14]. In the immune system, AIDS is caused by a virus and then allowed opportunistic infections and cancers, damage to flourish. Unprotected sexual intercourse [5, 6], contaminated medical devices (blood transfusions, surgery, and sharing needles) $[7,8]$, vertical transmission (pregnancy, childbirth, or breastfeeding) $[9,10]$, and body fluids make virus be transmitted through a population rapidly.

There were 35.3 million people living with HIV in 2012 (recorded by WHO). There are still no defined vaccines or drugs approval to kill all HIV virus in patient. The highly active antiretroviral therapy (HAART) is the standard of care for patients with advanced infection in current treatment [11].
HARRT is using a complex of transcription inhibitors to slow down transcription and then make the patient's total burden of HIV decrease, but this treatment is too expensive.

Recent studies indicate that viral infectivity factor (VIF) is an important goal of AIDS [12] in 2014. VIF is a protein in a lot retrovirus to degrade human enzyme APOBEC which can break down the unprotected virus. The virus can exist in human with VIF, thus the inhibition of VIF could help the immunity system to kill the virus.

Computer-aided drug design (CADD) is a technique for drug design based on computer simulation. The difference from traditional drug design is that CADD has the advantages of higher speed and lower cost to the screening of new compounds by the structure and biological activity of control, that is, two main applications named structure based and ligand based drug design of computer-aided drug design 


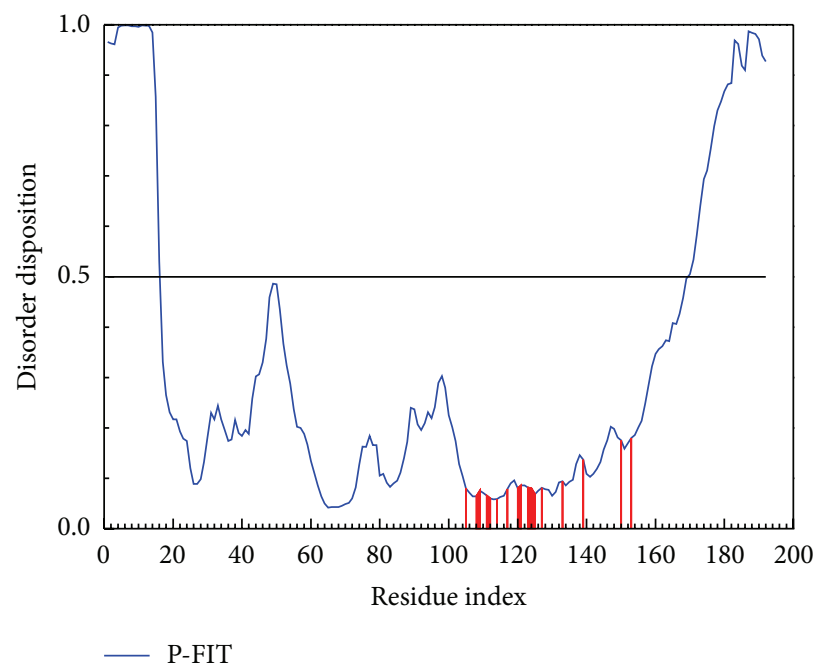

Figure 1: The disorder and binding site detection. The blue curve in the figure is the disorder disposition of each amino acid, and the red lines present the residues of the important amino acids for docking site.<smiles>[NH3+][C@@H](CCC(=O)[O-])C(=O)[O-]</smiles>

(a)<smiles>CC(C)=CCC[C@H](C(=O)O)[C@H]1CNC(N)=N1</smiles>

(b)<smiles>CC(=O)OC[C@H](Cc1ccccc1)NC(=O)[C@H](Cc1ccccc1)NC(=O)c1ccccc1</smiles>

(c)

FIGURE 2: The structure of control and candidate TCM compounds. (a) Glutamic acid, (b) plantagoguanidinic acid, and (c) Aurantiamide acetate.

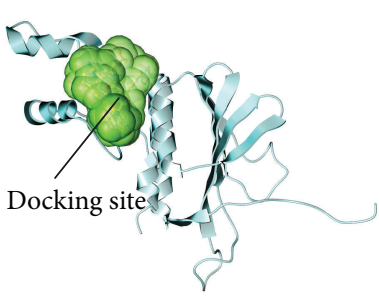

(a)

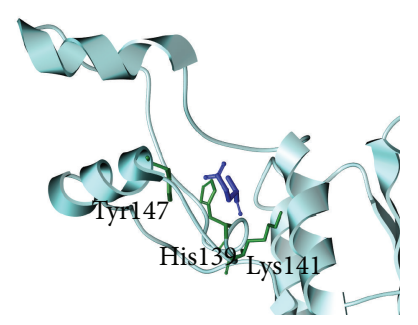

(b)

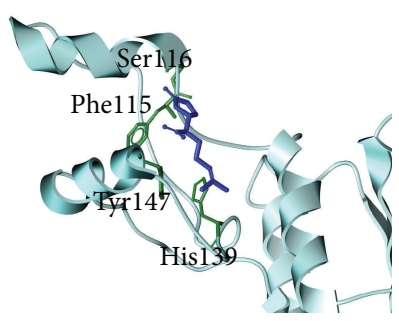

(c)

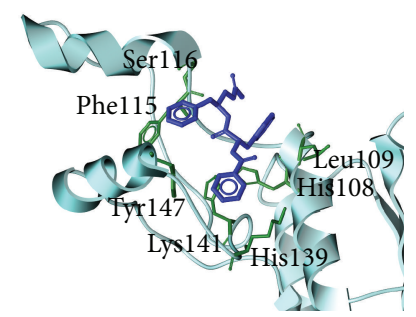

(d)

Figure 3: The docking poses of ligands. (a) The crystal structure of VIF and the designed docking site, (b) glutamic acid, (c) plantagoguanidinic acid, and (d) Aurantiamide acetate.

[13-18]. In this research, we use computer-aided drug design, molecular modeling in drug design basics to focus on drug design and molecular structure dynamics.

The personalized medicine and biomedicine are famous knowledge in these years. On the analysis of regional diseases [19], rare diseases [20], clinical diagnosis cases [21, 22], and disease associated mutations [23-25], this knowledge has drawn more and more attention $[26,27]$. Traditional Chinese medicine (TCM) is defined as a personalized medicine that has long been an important culture in Asia. The TCM Database@Taiwan (http://tcm.cmu.edu.tw/) [28] is the largest traditional Chinese medicine database in the world which has been established in 2011. This database has 2D chemical structure and 3D chemical structure, and the bioactivity of 61,000 compounds extracted from TCM herbs can be searched. Since 2011, the TCM Database@Taiwan application has been investigated for treatments of insomnia [29], pigmentary disorders [30], Parkinson's disease prevention [31], 


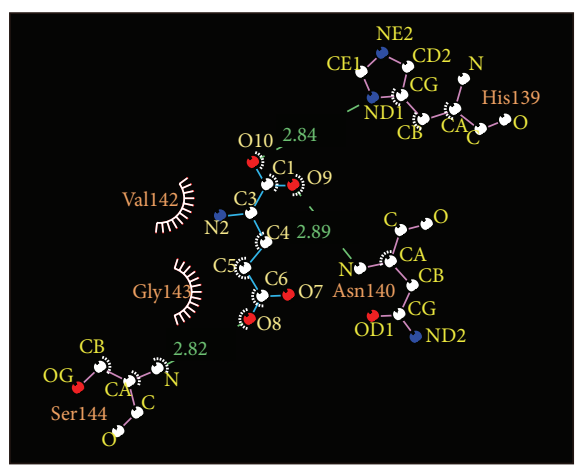

(a)

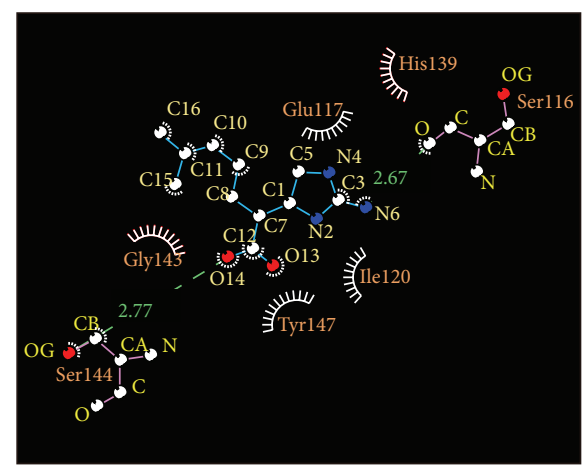

(b)

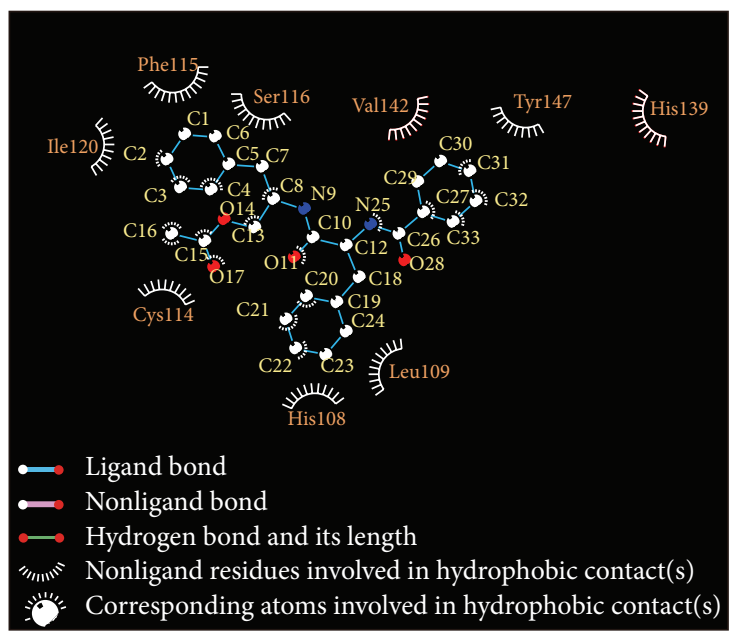

(c)

Figure 4: Ligplot illustrates the protein-ligand interactions. (a) Glutamic acid, (b) plantagoguanidinic acid, and (c) Aurantiamide acetate. The light red color of the hydrophobic interactions indicates a high frequency in all ligand interactions.

EGFR inhibition [32], pain relief [14], and antivirals [3337]. Recently, the TCM Database@Taiwan is helpful to screen TCM compounds via a cloud computing platform [38, 39].

In this research, we select TCM compounds to inhibit VIF by analyzing their interactions. The candidate compounds are selected based on the docking and structure variations and analyzed the interaction through molecular simulation.

\section{Materials and Methods}

2.1. Data Set. The traditional Chinese medicine compounds could be downloaded from the database (http://tcm.cmu.edu.tw/) and generate the small molecule compounds to identify potential VIF agonist screening.

The VIF protein sequences from UNIPROT acquired knowledge (P12504, HIV) and a three-dimensional structure of VIF protein could be offered from the Protein Data Bank (PDB ID: 4N9F) [12].

2.2. Structure Based Virtual Screening. The TCM compounds docking to VIF is performed by using LigandFit module in DS 2.5 [40]. Under Harvard molecular mechanics force field (CHARMM) [41], all docking posture chemistry is minimized. We make the DS 2.5 LigandFit module calculate piecewise linear potentiometer (-PLP) score and docking score. LIGPLUS [42, 43] calculates hydrogen bonding and hydrophobic contacts (hydrogen) during the ligand and protein interaction.

2.3. Disorder Prediction. We use PONDR-FIT program DisProt [44] exclusion VIF receptor site to define the character of three-dimensional structure. The comparison between disorder region and docking site could help the definition of drug efficacy.

2.4. Molecular Dynamics (MD) Simulations. We used chemical simulation package Groningen machine (GROMACS 4.5.5) to molecular dynamics simulations [45]. Before MD, these selected ligands must be prepared by using SwissParam (http://swissparam.ch/) [46] on the force field [47]. The complex is transferred to the buffer (or solution) simulation box. The distance between the complex and the box is $1.2 \AA$. This TIP3P water-solution model contains sodium and chloride 


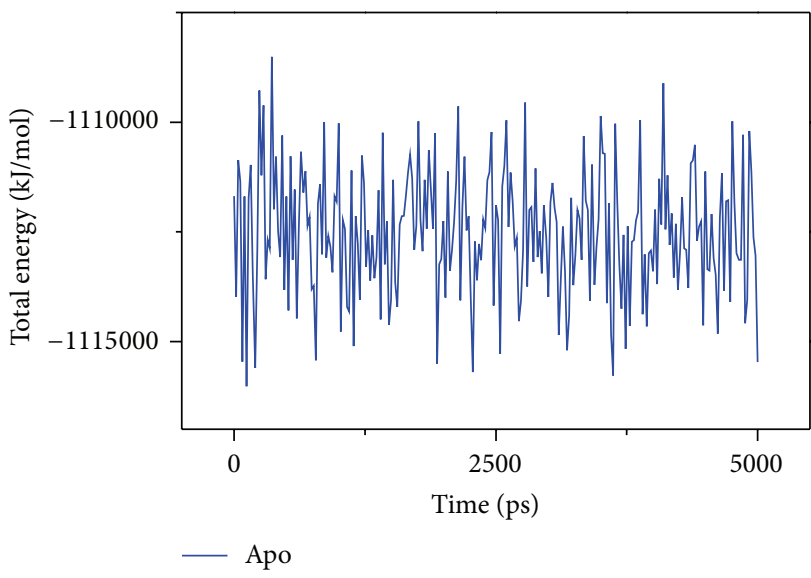

(a)

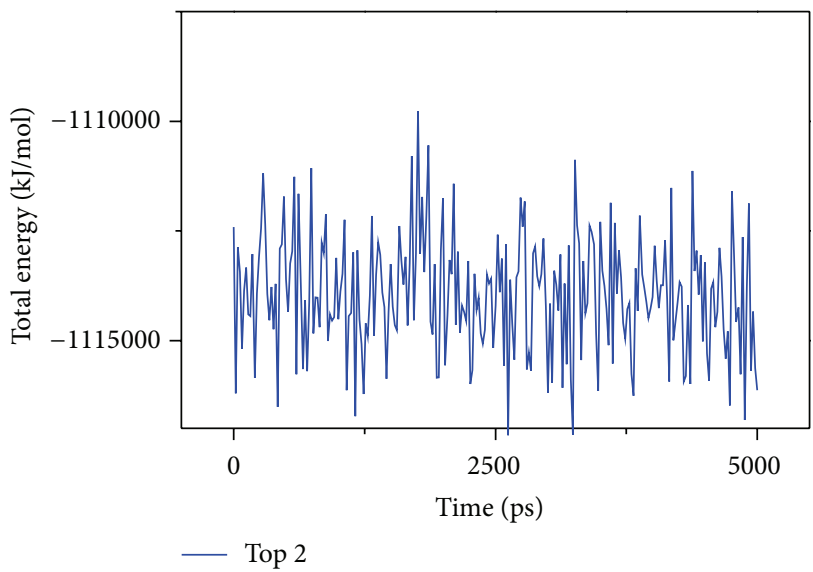

(c)

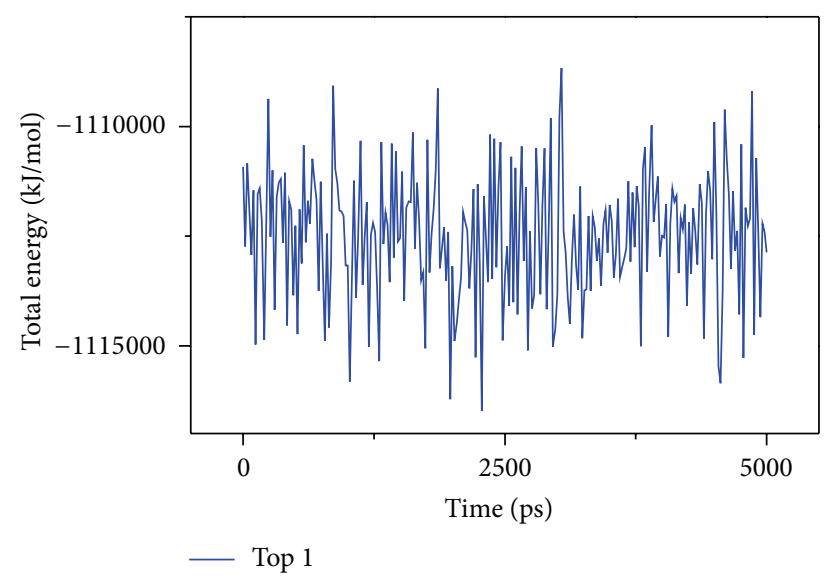

(b)

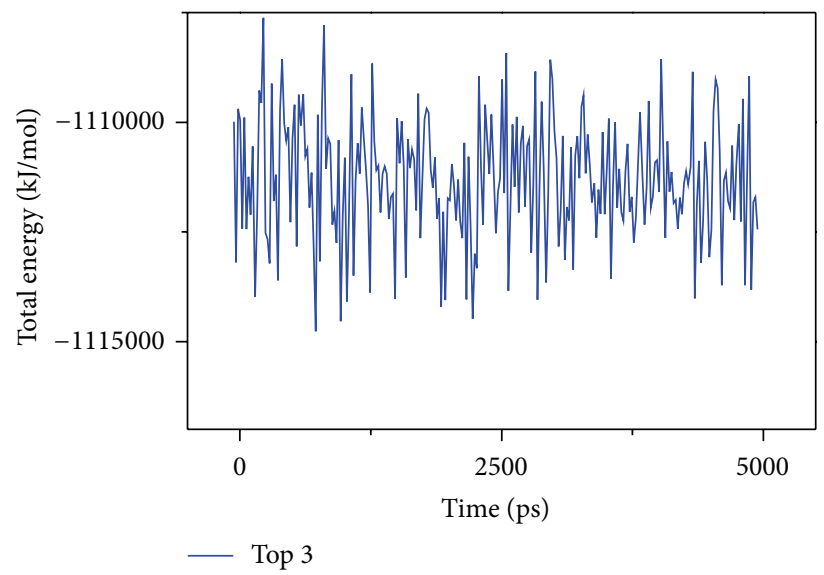

(d)

FIGURE 5: Measuring the energy variation of the complex. (a) Apo VIF, (b) glutamic acid, (c) plantagoguanidinic acid, (d) Aurantiamide acetate.

ions to neutralize complex charges full in box. The minimization used the steepest descent method for 5,000 steps; then the final structure with the lowest energy was transferred to $\mathrm{MD}$ simulation. The electrostatic interactions were calculated based on the particle mesh Ewald (PME) method with $2 \mathrm{fs}$ per time step for a total of 5,000,000 iterations [48]. The equilibration was under a 100 ps constant temperature (NVT ensemble) based on the Berendsen weak thermal coupling method. The minimum distance of the root locus analysis of digital root mean square deviation (RMSD), total energy, RMS fluctuations (RMSF), residue matrix database structure assignment (DSSP), and cluster analysis could be calculated from the program of MD simulations.

2.5. FasL Pathway. We use the software caver 3.0 to analyze all possible ways interpath protein path during MD simulation [49].

\section{Results and Discussion}

3.1. Disorder Prediction. Protein disorder is defined as an unstructured protein, and such characters for the docking site will make drug docking to the protein as complex difficultly. The references $[50,51]$ present that protein disorder is not a common domain; thus, the drug might have less side effects during the interaction. For the above reasons, disorder for drug design is not a bad situation, and it should be defined as difficult work only. The important amino acids of VIF Gln105, His108, Leu109, Tyr111, Phe112, Cys114, Glu117, Ile120, Arg121, Thr123, Ile124, Leu125, Arg127, Cys133, His139, Leu150, and Ile153 are defined as nondisorder regions (Figure 1). For the result, the selected compound dock to VIF will not be difficult.

3.2. Docking. The top three TCM compounds can be selected from the database according to the rank of the result of molecular docking by docking score (Table 1). These TCM compounds are glutamic acid, plantagoguanidinic acid, and Aurantiamide acetate extract from the TCM herbs Achyranthes bidentata Bl., Plantago asiatica L., and Cordyceps sinensis (Berk.) Sacc (or Sargassum pallidum (Turn.) and Lycium chinense Miller). The top compound, glutamic acid, is extracted from Achyranthes bidentata Bl. with the function to develop 


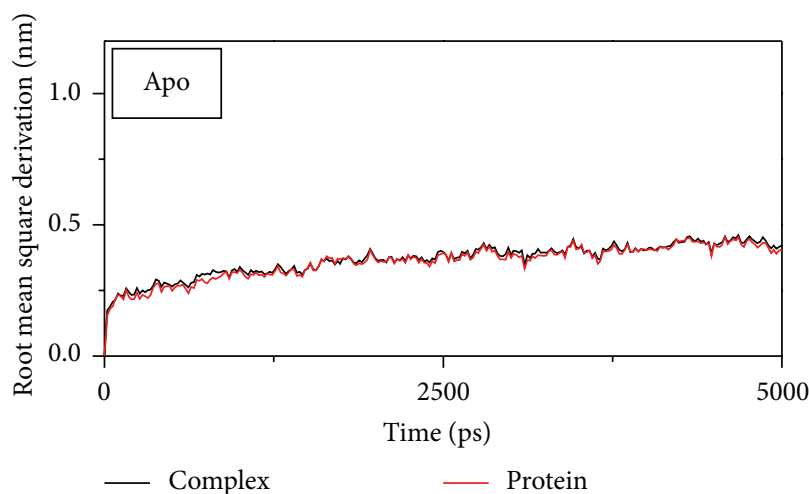

(a)

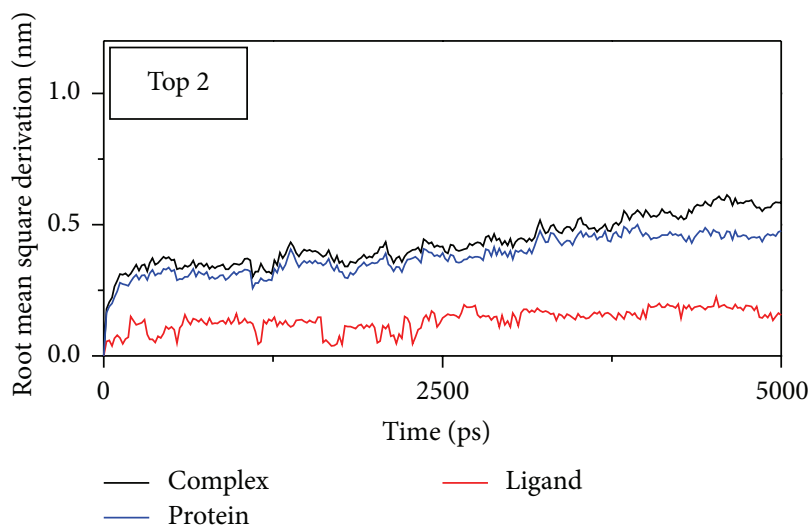

(c)

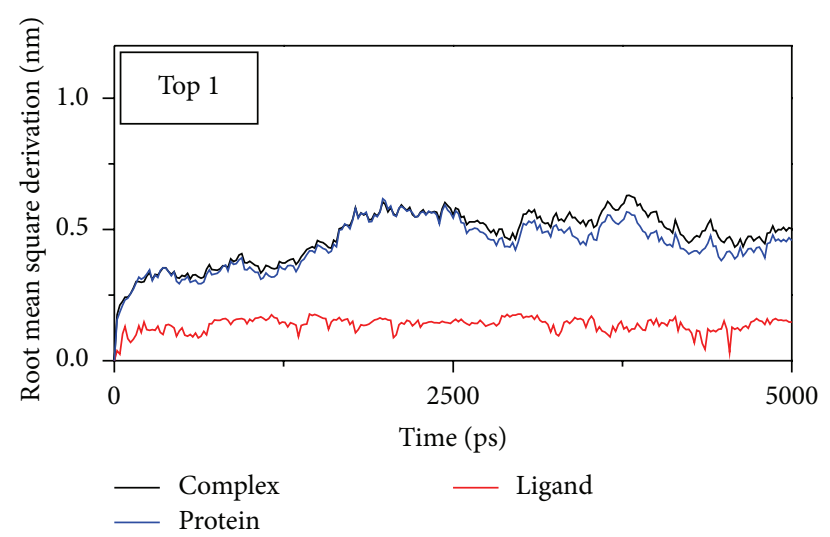

(b)

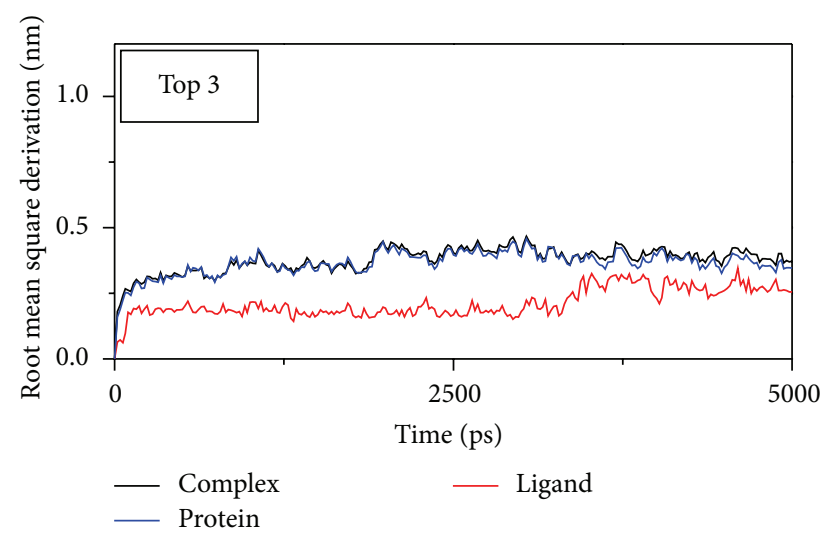

(d)

Figure 6: Measures the RMSD variation of the complex. (a) Apo VIF, (b) glutamic acid, (c) plantagoguanidinic acid, and (d) Aurantiamide acetate.

TABLE 1

\begin{tabular}{lcccc}
\hline Name & Herb & $\begin{array}{c}\text { Dock } \\
\text { score }\end{array}$ & -PLP1 & -PLP2 \\
\hline $\begin{array}{l}\text { Glutamic acid } \\
\text { Plantagoguanidinic } \\
\text { acid }\end{array}$ & $\begin{array}{c}\text { Achyranthes bidentata } \\
\text { Bl. }\end{array}$ & 175.136 & 32.52 & 29.59 \\
& $\begin{array}{c}\text { Plantago asiatica L. } \\
\text { Aurantiamide }\end{array}$ & 91.191 & 47.61 & 44.23 \\
acetate & $\begin{array}{c}\text { Sargassum pallidum } \\
\text { (Turn.)/Cordyceps } \\
\text { sinensis (Berk.) }\end{array}$ & 82.182 & 70.96 & 66.45 \\
& $\begin{array}{c}\text { Sacc./Lycium chinense } \\
\text { Miller }\end{array}$ & & & \\
\hline
\end{tabular}

immunity $[52,53]$. The second ranked herb, plantagoguanidinic acid, with the herb Plantago asiatica $\mathrm{L}$. had been defined owing to the function of antiviral and immunomodulatory $[54,55]$. The third ranked compound, Aurantiamide acetate, could be extracted from the herb Sargassum pallidum (Turn.), Cordyceps sinensis (Berk.) Sacc., and Lycium chinense Miller. These herbs have recorded the function to improve the immunity [56-62]. From these references, we suggest our selected compounds might inhibit VIF from the immunity regulation.
The structure of the candidate compounds selected after screening is shown in (Figure 2). The docking poses show the docking site and the important amino acid near ligands (Figure 3). From this result, we observe some amino acids may play important roles in a VIF target function.

The hydrophobic interaction can be analyzed by LIGPLUS (Figure 4). This result shows that the amino acids His139 can have interactions with the ligands through hydrophobic interactions or hydrogen bonds that might be as important as amino while the selected compounds have an effect on VIF.

3.3. Molecular Simulation. The RMSD and total energy of a complex during MD simulation were recorded (Figures 57). The total energy is in the range of $-111.5 \sim-111 * 10^{3} \mathrm{~kJ} / \mathrm{mol}$. The amplitude is gentle; then, we suggest the interaction for VIF and compounds tend to balance (Figure 5). In these compounds, the top 2 plantagoguanidinic acid has the lowest energy that means the complex might be the most stable. The complex RMSD in top 1 and top 2 is different from protein, which might mean that ligand moves away from the docking site (Figure 6). In Figure 6, we also find that the top 3 


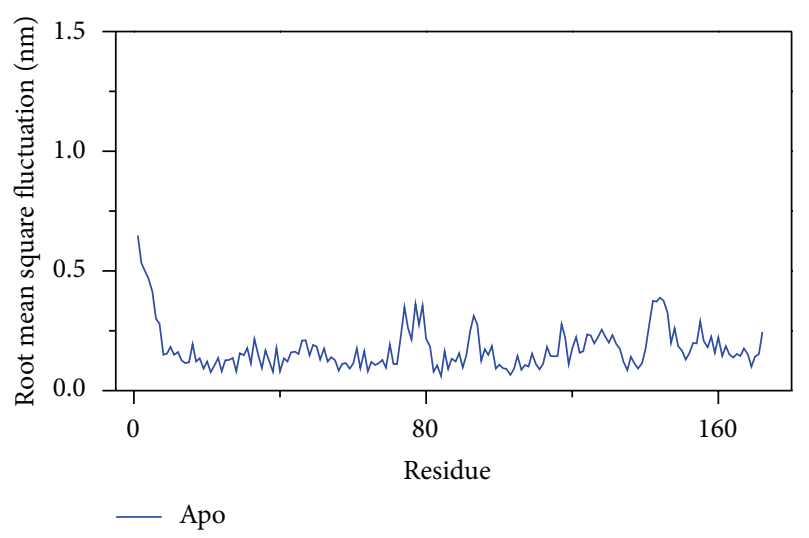

(a)

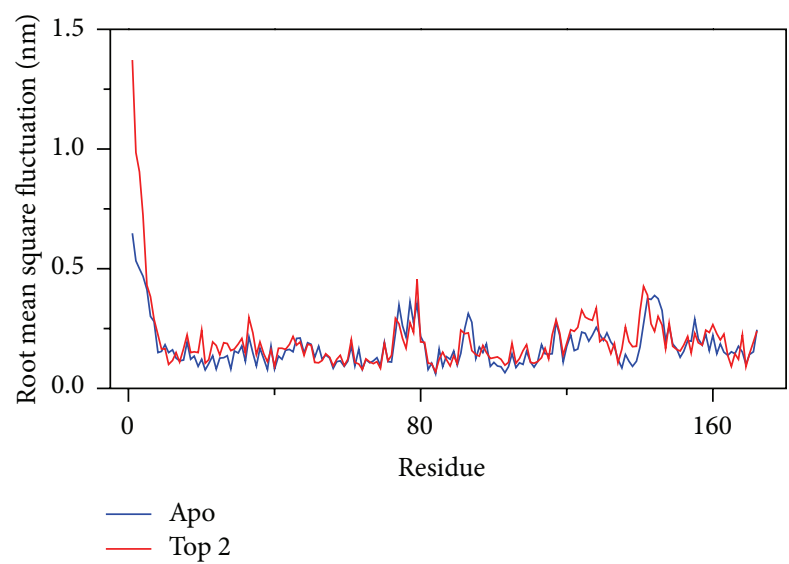

(c)

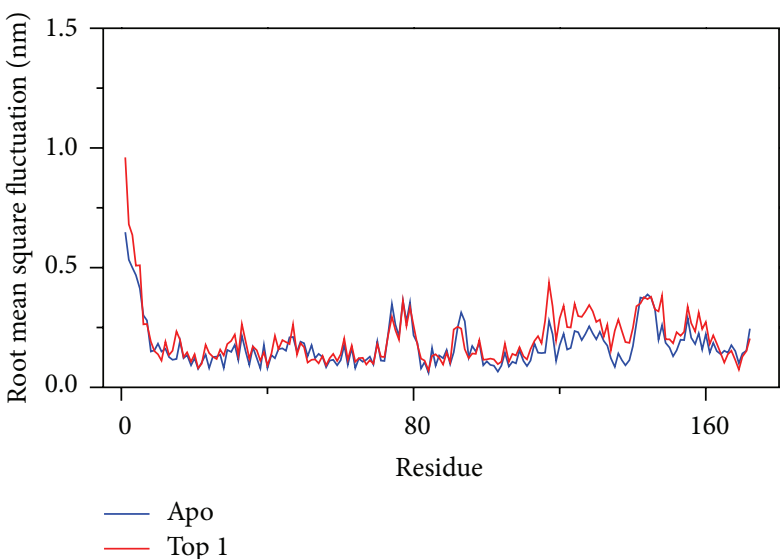

(b)

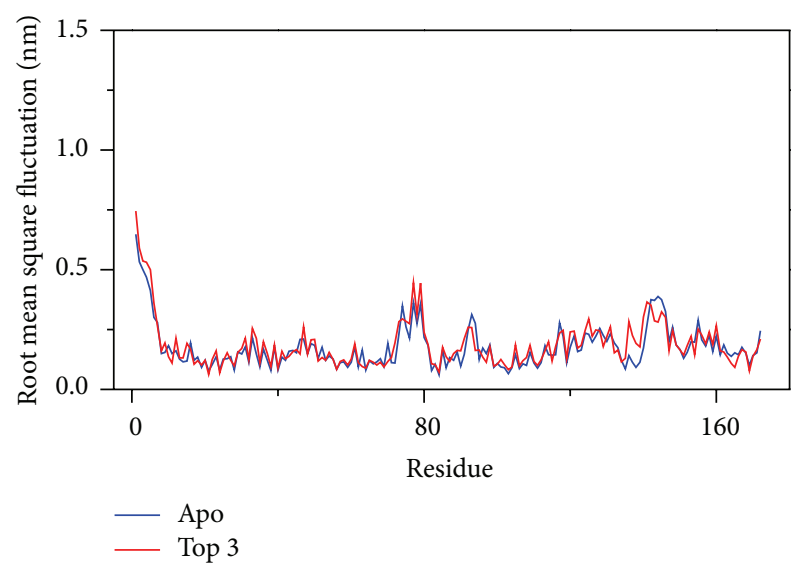

(d)

FIGURE 7: The variation of RMSD focuses on residue of protein and compares with apo (unbound protein). (a) Apo VIF and apo compare with (b) glutamic acid, (c) plantagoguanidinic acid, and (d) Aurantiamide acetate.

Aurantiamide acetates have the lowest RMSD among others (contain apo/unbound protein). The variation of ligand is continue might present Aurantiamide acetate interaction with VIF will make the complex stable.

The RMSD focus on each residue (means RMSF) could detect the variation of protein during interaction (Figure 7). In this result, we can find that the pick sites of protein with ligand interaction are similar to apo protein and the value is larger than apo protein, which means the docking site is designed as the functional site and ligands interactions affect these residues by different force.

The clustering is based on RMSD variation to divide data into several groups. This clustering method could make the similar structure in the same group (Figure 8). In this figure, complex with ligands will have more groups than apo. It might be presented that the ligands target to VIF might make larger structure variation and then inhibit the function of protein.

After the analysis of interaction, we should pay attention to the structure variation after the force of interaction
(Figures 9, 10, and 11). In Figures 9(a) to 11(a), we could find that the $\mathrm{H}$ bond between protein and ligand is less. We suggest that the protein wants to prevent ligand target on the functional site; then the character of protein will make drug effect hardly. Besides Aurantiamide acetate, the structure variations of compounds interaction are only position variation; thus, we suggest that only the Aurantiamide acetate could have better efficacy for the inhibition of VIF.

The pathway for ligand shows the path in protein (Figure 12). In this result, most of pathways are around the docking site, which indicates that the functional site might be focused on docking site and the protein has no other pole for the interaction.

\section{Conclusion}

In this study, the structure of computer-aided drug design is based on the theory of traditional Chinese medicine ligand screening compounds to inhibit the VIF. The compounds 


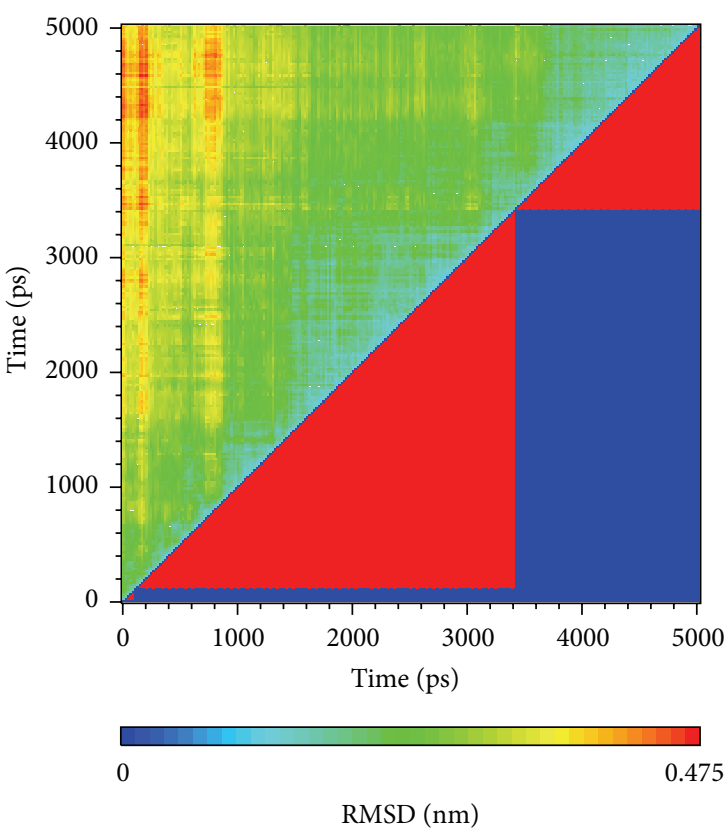

(a)

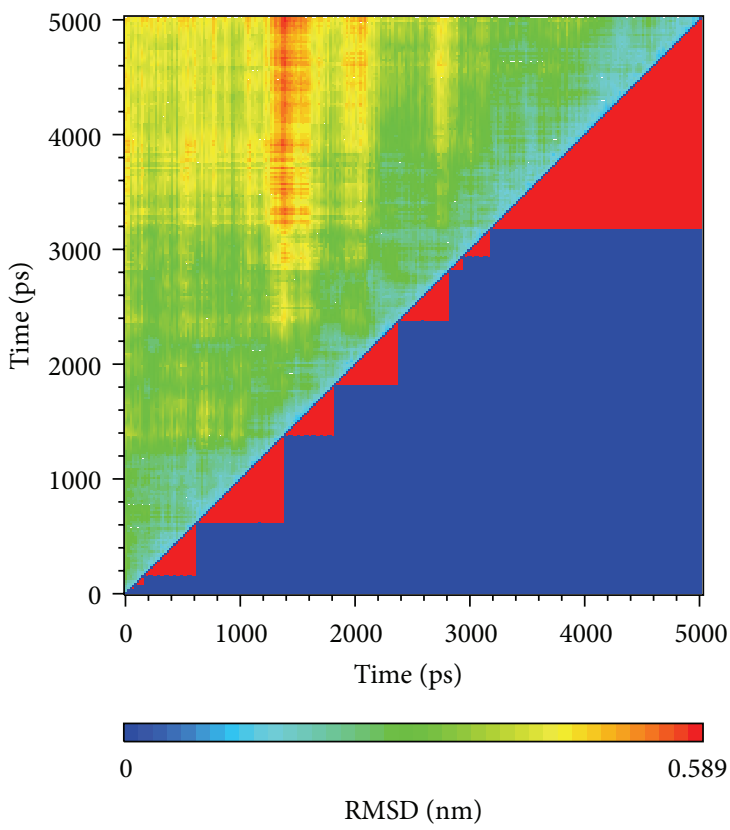

(c)

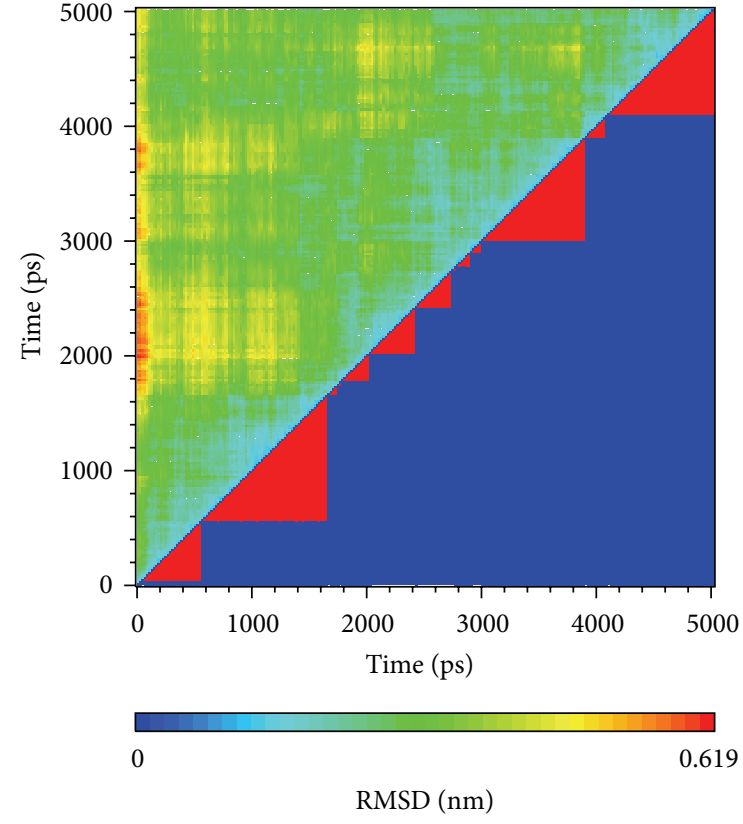

(b)

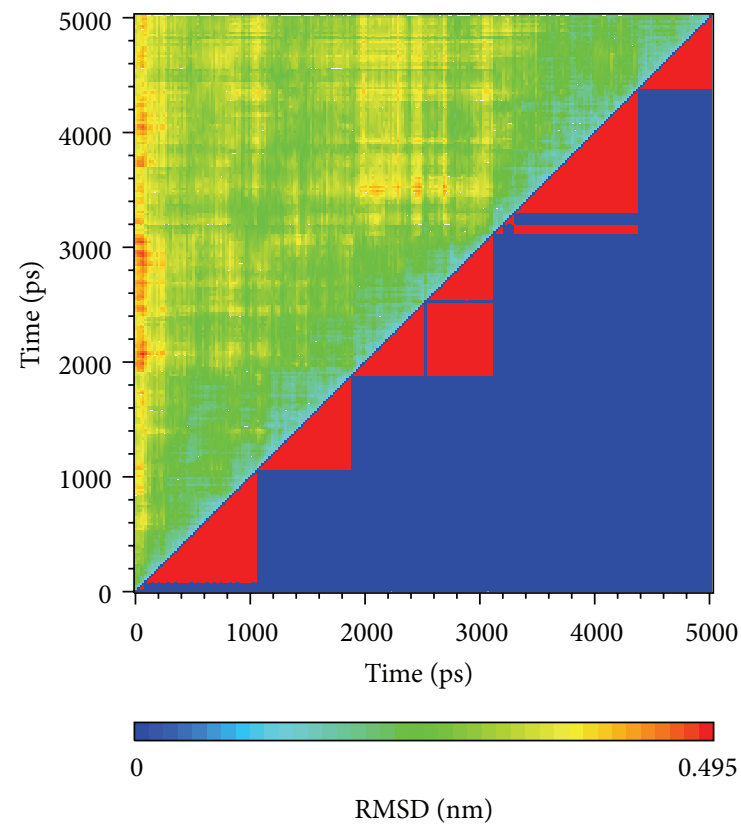

(d)

FIgURE 8: The clustering of the ligand-protein interaction. (a) Apo VIF, (b) glutamic acid, (c) plantagoguanidinic acid, and (d) Aurantiamide acetate.

glutamic acid, plantagoguanidinic acid, and Aurantiamide acetate are selected from TCM database through several calculations to analyze the interaction and variation. Then, according to the RMSD, $\mathrm{H}$ bond interaction, and structure variation, we find the selected compounds move away from the docking site besides Aurantiamide acetate; this situation for drug design is not well. Thus, according to the simulation, we suggest that Aurantiamide acetate may the best compound to inhibit VIF and then help immunity to prevent HIV virus.

\section{Conflict of Interests}

The authors confirm that this paper content has no conflict of interests. 


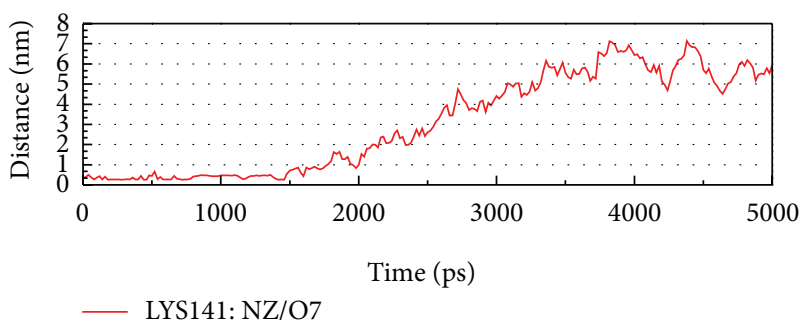

(a)

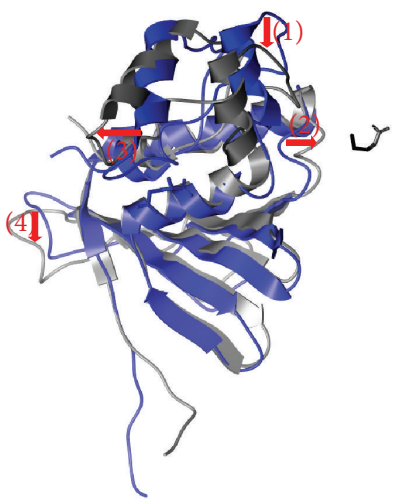

(b)

Figure 9: The variation of glutamic acid and VIF complex in MD simulation. (a) H-bond variation, (b) structure variation. The (1)-(4) red color indicates the difference through MD.

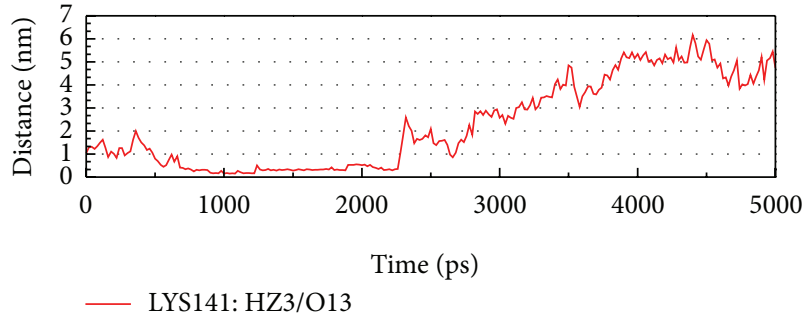

(a)

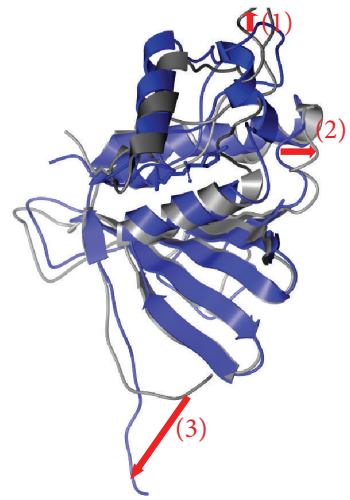

(b)

FIGURE 10: The variation of plantagoguanidinic acid and VIF complex in MD simulation. (a) H-bond variation, (b) structure variation. The (1)-(3) red color indicates the difference through MD.

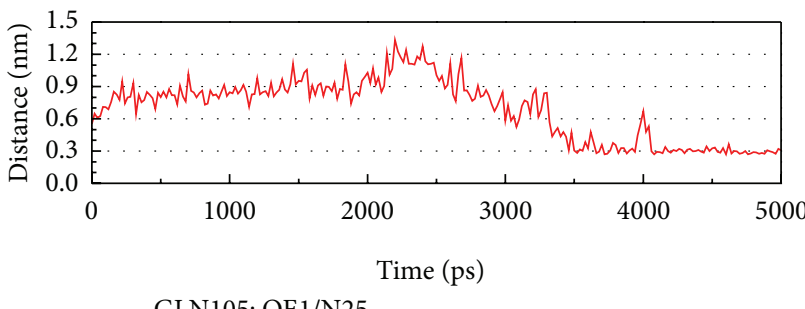

(a)

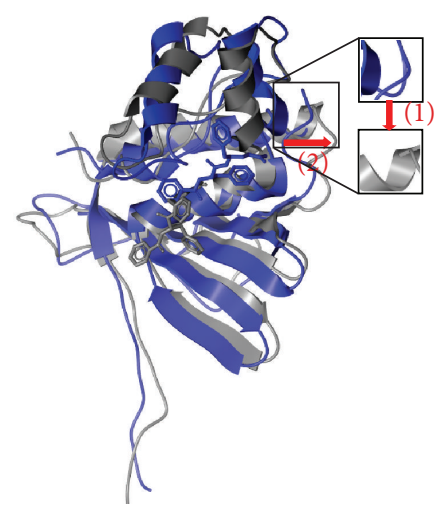

(b)

FIgURE 11: The variation of Aurantiamide acetate and VIF complex in MD simulation. (a) H-bond variation, (b) structure variation. The (1)-(2) red color indicates the difference through MD. 


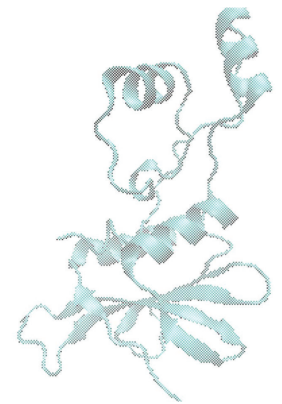

(a)

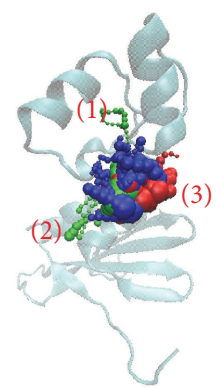

(b)

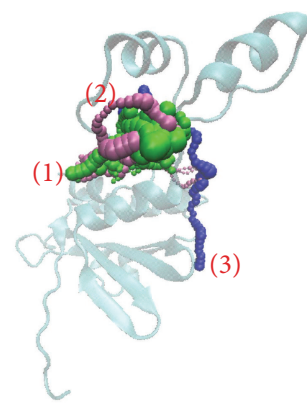

(c)

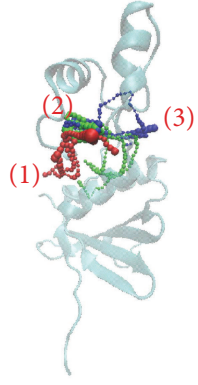

(d)

Figure 12: The pathway of VIF for compounds. (a) Apo VIF, (b) glutamic acid, (c) plantagoguanidinic acid, and (d) Aurantiamide acetate.

\section{Authors' Contribution}

Tzu-Chieh Hung, Wen-Yuan Lee and Kuen-Bao Chen contributed equally to this work.

\section{Acknowledgments}

The research was supported by grants from the National Science Council of Taiwan (NSC102-2325-B039-001, NSC102-2221-E-468-027-), Asia University (Asia101-CMU2, 102-Asia-07), and China Medical University Hospital (DMR-103-058, DMR-103-001, and DMR-103-096). This study is also supported in part by Taiwan Department of Health Clinical Trial and Research Center of Excellence (DOH102-TD-B-111-004) and Taiwan Department of Health Cancer Research Center of Excellence (MOHW103-TD-B111-03) and CMU under the Aim for Top University Plan of the Ministry of Education, Taiwan.

\section{References}

[1] F. Barre Sinoussi, J. C. Chermann, and F. Rey, "Isolation of a T-lymphotropic retrovirus from a patient at risk for acquired immune deficiency syndrome (AIDS)," Science, vol. 220, no. 4599, pp. 868-871, 1983.

[2] M. W. Cloyd, J. J.-Y. Chen, and L. Wang, "How does HIV cause AIDS? The homing theory," Molecular Medicine Today, vol. 6, no. 3, pp. 108-111, 2000.

[3] R. A. Weiss, "How does HIV cause AIDS?" Science, vol. 260, no. 5112, pp. 1273-1279, 1993.

[4] D. C. Douek, M. Roederer, and R. A. Koup, "Emerging concepts in the immunopathogenesis of AIDS," Annual Review of Medicine, vol. 60, pp. 471-484, 2009.

[5] S. Weller and K. Davis, "Condom effectiveness in reducing heterosexual HIV transmission," The Cochrane Database of Systematic Reviews, no. 1, Article ID CD003255, 2002.

[6] B. Leynaert, A. M. Downs, and I. de Vincenzi, "Heterosexual transmission of human immunodeficiency virus: variability of infectivity throughout the course of infection," The American Journal of Epidemiology, vol. 148, no. 1, pp. 88-96, 1998.

[7] D. M. Bell, "Occupational risk of human immunodeficiency virus infection in healthcare workers: an overview," The American Journal of Medicine B, vol. 102, no. 5, pp. 9-15, 1997.

[8] J. L. Cleveland, L. Barker, B. F. Gooch, E. M. Beltrami, and D. Cardo, "Use of HIV postexposure prophylaxis by dental health care personnel: an overview and updated recommendations," Journal of the American Dental Association, vol. 133, no. 12, pp. 1619-1626, 2002.

[9] J. C. Forbes, A. M. Alimenti, J. Singer et al., "A national review of vertical HIV transmission," AIDS, vol. 26, no. 6, pp. 757-763, 2012.

[10] K. M. Little, P. H. Kilmarx, A. W. Taylor, C. E. Rose, E. D. Rivadeneira, and S. R. Nesheim, "A review of evidence for transmission of HIV from children to breastfeeding women and implications for prevention," Pediatric Infectious Disease Journal, vol. 31, no. 9, pp. 938-942, 2012.

[11] D. Finzi, M. Hermankova, T. Pierson et al., "Identification of a reservoir for HIV-1 in patients on highly active antiretroviral therapy," Science, vol. 278, no. 5341, pp. 1295-1300, 1997.

[12] Y. Guo, L. Dong, X. Qiu et al., "Structural basis for hijacking CBF-beta and CUL5 E3 ligase complex by HIV-1 Vif," Nature, vol. 505, no. 7482, pp. 229-233, 2014.

[13] H. J. Huang, H. W. Yu, C. Y. Chen et al., "Current developments of computer-aided drug design," Journal of the Taiwan Institute of Chemical Engineers, vol. 41, no. 6, pp. 623-635, 2010.

[14] W. I. Tou, S.-S. Chang, C.-C. Lee, and C. Y.-C. Chen, "Drug design for neuropathic pain regulation from traditional Chinese medicine," Scientific Reports, vol. 3, p. 844, 2013.

[15] C. Y.-C. Chen, "A novel integrated framework and improved methodology of computer-aided drug design," Current Topics in Medicinal Chemistry, vol. 13, no. 9, pp. 965-988, 2013.

[16] C. Y.-C. Chen and W. I. Tou, "How to design a drug for the disordered proteins?” Drug Discovery Today, vol. 18, no. 19-20, pp. 910-915, 2013.

[17] S. C. Basak, "Recent developments and future directions at current computer aided drug design," Current Computer-Aided Drug Design, vol. 9, no. 1, p. 1, 2013.

[18] C. Y.-C. Chen, "Weighted equation and rules-a novel concept for evaluating protein-ligand interaction," Journal of Biomolecular Structure and Dynamics, vol. 27, no. 3, pp. 271-282, 2009.

[19] C.-C. Lee, C.-H. Tsai, L. Wan et al., "Increased incidence of parkinsonism among Chinese with $\beta$-glucosidase mutation in central Taiwan," BioMedicine, vol. 3, no. 2, pp. 92-94, 2013.

[20] F.-J. Tsai, "Rare diseases: a mysterious puzzle," BioMedicine, vol. 3, no. 2, article 65, 2013.

[21] C.-H. Wang, W.-D. Lin, and F.-J. Tsai, "Craniofacial dysmorphism, what is your diagnosis?” BioMedicine, vol. 2, no. 2, pp. 49-50, 2012.

[22] Y.-T. Chang, W.-D. Lin, Z.-N. Chin et al., "Nonketotic hyperglycinemia: a case report and brief review," BioMedicine, vol. 2, no. 2, pp. 80-82, 2012. 
[23] I. C. Chou, W.-D. Lin, and C.-H. Wang, "Möbius syndrome in a male with XX/XY mosaicism," BioMedicine, vol. 3, no. 2, pp. 102-104, 2013.

[24] I.-C. Chou, W.-D. Lin, C.-H. Wang et al., "Association analysis between Tourette's syndrome and two dopamine genes (DAT1, DBH) in Taiwanese children," BioMedicine, vol. 3, no. 2, pp. 8891, 2013.

[25] W.-Y. Lin, H.-P. Liu, J.-S. Chang et al., "Genetic variations within the PSORS1 region affect Kawasaki disease development and coronary artery aneurysm formation," BioMedicine, vol. 3, no. 2, pp. 73-81, 2013.

[26] W.-L. Liao and F.-J. Tsai, "Personalized medicine: a paradigm shift in healthcare," BioMedicine, vol. 3, no. 2, pp. 66-72, 2013.

[27] F.-J. Tsai, "Biomedicine brings the future nearer," BioMedicine, vol. 1, no. 1, p. 1, 2011.

[28] C. Y.-C. Chen, “TCM Database@Taiwan: the world's largest traditional Chinese medicine database for drug screening in silico," PLoS ONE, vol. 6, no. 1, Article ID e15939, 2011.

[29] H. Y. Chen, S. S. Chang, Y. C. Chan, and C. Y. Chen, "Discovery of novel insomnia leads from screening traditional Chinese medicine database," Journal of Biomolecular Structure \& Dynamics, vol. 32, no. 5, pp. 776-791, 2014.

[30] H.-C. Tang and C. Y.-C. Chen, "Investigation of the novel lead of melanocortin 1 receptor for pigmentary disorders," Evidence-Based Complementary and Alternative Medicine, vol. 2014, Article ID 254678, 13 pages, 2014.

[31] H.-J. Huang, C.-C. Lee, and C. Y.-C. Chen, "Pharmacological chaperone design for reducing risk factor of parkinson's disease from traditional Chinese medicine," Evidence-Based Complementary and Alternative Medicine, vol. 2014, Article ID 830490, 12 pages, 2014.

[32] S.-C. Yang, S.-S. Chang, H.-Y. Chen, and C. Y.-C. Chen, "Identification of potent EGFR inhibitors from TCM database@Taiwan,” PLoS Computational Biology, vol. 7, no. 10, Article ID e1002189, 2011.

[33] S.-S. Chang, H.-J. Huang, and C. Y.-C. Chen, "High performance screening, structural and molecular dynamics analysis to identify H1 inhibitors from TCM database@Taiwan," Molecular BioSystems, vol. 7, no. 12, pp. 3366-3374, 2011.

[34] C.-H. Lin, T.-T. Chang, M.-F. Sun et al., "Potent inhibitor design against H1N1 swine influenza: structure-based and molecular dynamics analysis for M2 inhibitors from traditional Chinese medicine database," Journal of Biomolecular Structure and Dynamics, vol. 28, no. 4, pp. 471-482, 2011.

[35] S.-S. Chang, H.-J. Huang, and C. Y.-C. Chen, "Two birds with one stone? Possible dual-targeting H1N1 inhibitors from traditional Chinese medicine," PLoS Computational Biology, vol. 7, no. 12, Article ID e1002315, 2011.

[36] C.-Y. Chen, Y.-H. Chang, D.-T. Bau et al., "Ligand-based dual target drug design for H1N1: swine flu-a preliminary first study," Journal of Biomolecular Structure and Dynamics, vol. 27, no. 2, pp. 171-178, 2009.

[37] H. J. Huang, Y. R. Jian, and C. Y. Chen, "Traditional Chinese medicine application in HIV: an in silico study," Journal of Biomolecular Structure \& Dynamics, vol. 32, no. 1, pp. 1-12, 2014.

[38] T.-Y. Tsai, K.-W. Chang, and C. Y.-C. Chen, "IScreen: world's first cloud-computing web server for virtual screening and de novo drug design based on TCM database@Taiwan," Journal of Computer-Aided Molecular Design, vol. 25, no. 6, pp. 525-531, 2011.
[39] K.-W. Chang, T.-Y. Tsai, K.-C. Chen et al., "iSMART: an integrated cloud computing web server for traditional Chinese medicine for online virtual screening, de novo evolution and drug design," Journal of Biomolecular Structure and Dynamics, vol. 29, no. 1, pp. 243-250, 2011.

[40] C. M. Venkatachalam, X. Jiang, T. Oldfield, and M. Waldman, "LigandFit: a novel method for the shape-directed rapid docking of ligands to protein active sites," Journal of Molecular Graphics and Modelling, vol. 21, no. 4, pp. 289-307, 2003.

[41] B. R. Brooks, C. L. Brooks III, A. D. Mackerell Jr. et al., "CHARMM: the biomolecular simulation program," Journal of Computational Chemistry, vol. 30, no. 10, pp. 1545-1614, 2009.

[42] R. A. Laskowski and M. B. Swindells, "LigPlot+: multiple ligandprotein interaction diagrams for drug discovery," Journal of Chemical Information and Modeling, vol. 51, no. 10, pp. 27782786, 2011.

[43] A. C. Wallace, R. A. Laskowski, and J. M. Thornton, "LIGPLOT: a program to generate schematic diagrams of protein-ligand interactions," Protein Engineering, vol. 8, no. 2, pp. 127-134, 1995.

[44] B. Xue, R. L. Dunbrack, R. W. Williams, A. K. Dunker, and V. N. Uversky, "PONDR-FIT: a meta-predictor of intrinsically disordered amino acids," Biochimica et Biophysica Acta-Proteins and Proteomics, vol. 1804, no. 4, pp. 996-1010, 2010.

[45] B. Hess, C. Kutzner, D. van der Spoel, and E. Lindahl, "GRGMACS 4: algorithms for highly efficient, load-balanced, and scalable molecular simulation," Journal of Chemical Theory and Computation, vol. 4, no. 3, pp. 435-447, 2008.

[46] V. Zoete, M. A. Cuendet, A. Grosdidier, and O. Michielin, "SwissParam: a fast force field generation tool for small organic molecules," Journal of Computational Chemistry, vol. 32, no. 11, pp. 2359-2368, 2011.

[47] U. D. Priyakumar and A. D. MacKerell, "Comparison of the CHARMM27, AMBER4.1 and BMS nucleic acid force fields via free energy calculations of base flipping," Abstracts of Papers of the American Chemical Society, vol. 230, pp. U1391-U1392, 2005.

[48] T. A. Darden and L. G. Pedersen, "Molecular modeling: an experimental tool," Environmental Health Perspectives, vol. 101, no. 5, pp. 410-412, 1993.

[49] E. Chovancova, A. Pavelka, P. Benes et al., "CAVER 3.0: a tool for the analysis of transport pathways in dynamic protein structures," PLoS Computational Biology, vol. 8, no. 10, Article ID e1002708, 2012.

[50] C. Y.-C. Chen and W. I. Tou, "How to design a drug for the disordered proteins?” Drug Discovery Today, 2013.

[51] C. Y. C. Chen and W. L. Tou, "How to design a drug for the disordered proteins," Drug Discovery Today, vol. 18, no. 19-20, pp. 910-915, 2013.

[52] X. Zhu, Y. Pan, L. Zheng, L. Cui, and Y. Cao, "Polysaccharides from the Chinese medicinal herb Achyranthes bidentata enhance anti-malarial immunity during Plasmodium yoelii 17XL infection in mice," Malaria Journal, vol. 11, p. 49, 2012.

[53] Q. Chen, Z. Liu, and J. H. He, "Achyranthes bidentata polysaccharide enhances immune response in weaned piglets," Immunopharmacology and Immunotoxicology, vol. 31, no. 2, pp. 253-260, 2009.

[54] H. Yamada, T. Nagai, N. Takemoto et al., "Plantagoside, a novel $\alpha$-mannosidase inhibitor isolated from the seeds of Plantago asiatica, suppresses immune response," Biochemical and Biophysical Research Communications, vol. 165, no. 3, pp. 1292-1298, 1989. 
[55] L. C. Chiang, W. Chiang, M. Y. Chang, and C. C. Lin, "In vitro cytotoxic, antiviral and immunomodulatory effects of Plantago major and Plantago asiatica," The American Journal of Chinese Medicine, vol. 31, no. 2, pp. 225-234, 2003.

[56] R.-L. Zhang, W.-D. Luo, T.-N. Bi, and S.-K. Zhou, "Evaluation of antioxidant and immunity-enhancing activities of sargassum pallidum aqueous extract in gastric cancer rats," Molecules, vol. 17, no. 7, pp. 8419-8429, 2012.

[57] S.-J. Zhu, J. Pan, B. Zhao, J. Liang, W. Ze-yu, and J.-J. Yang, "Comparisons on enhancing the immunity of fresh and dry Cordyceps militaris in vivo and in vitro," Journal of Ethnopharmacology, vol. 149, no. 3, pp. 713-719, 2013.

[58] M.-H. Jeong, C.-M. Lee, S.-W. Lee et al., "Cordycepinenriched Cordyceps militaris induces immunomodulation and tumor growth delay in mouse-derived breast cancer," Oncology Reports, vol. 30, no. 4, pp. 1996-2002, 2013.

[59] D. Song, Z. He, C. Wang, F. Yuan, P. Dong, and W. Zhang, "Regulation of the exopolysaccharide from an anamorph of Cordyceps sinensis on dendritic cell sarcoma (DCS) cell line," European Journal of Nutrition, vol. 52, no. 2, pp. 687-694, 2013.

[60] Z.-Y. Zhu, J. Chen, C.-L. Si et al., "Immunomodulatory effect of polysaccharides from submerged cultured Cordyceps gunnii," Pharmaceutical Biology, vol. 50, no. 9, pp. 1103-1110, 2012.

[61] M.-H. Jeong, M. J. Seo, J. U. Park et al., "Effect of cordycepin purified from Cordyceps militaris on Th1 and Th2 cytokines in mouse splenocytes," Journal of Microbiology and Biotechnology, vol. 22, no. 8, pp. 1161-1164, 2012.

[62] J.-Z. Dong, J.-J. Yang, and Y. Wang, "Resources of Lycium species and related research progress," Zhongguo Zhongyao Zazhi, vol. 33, no. 18, pp. 2020-2027, 2008. 

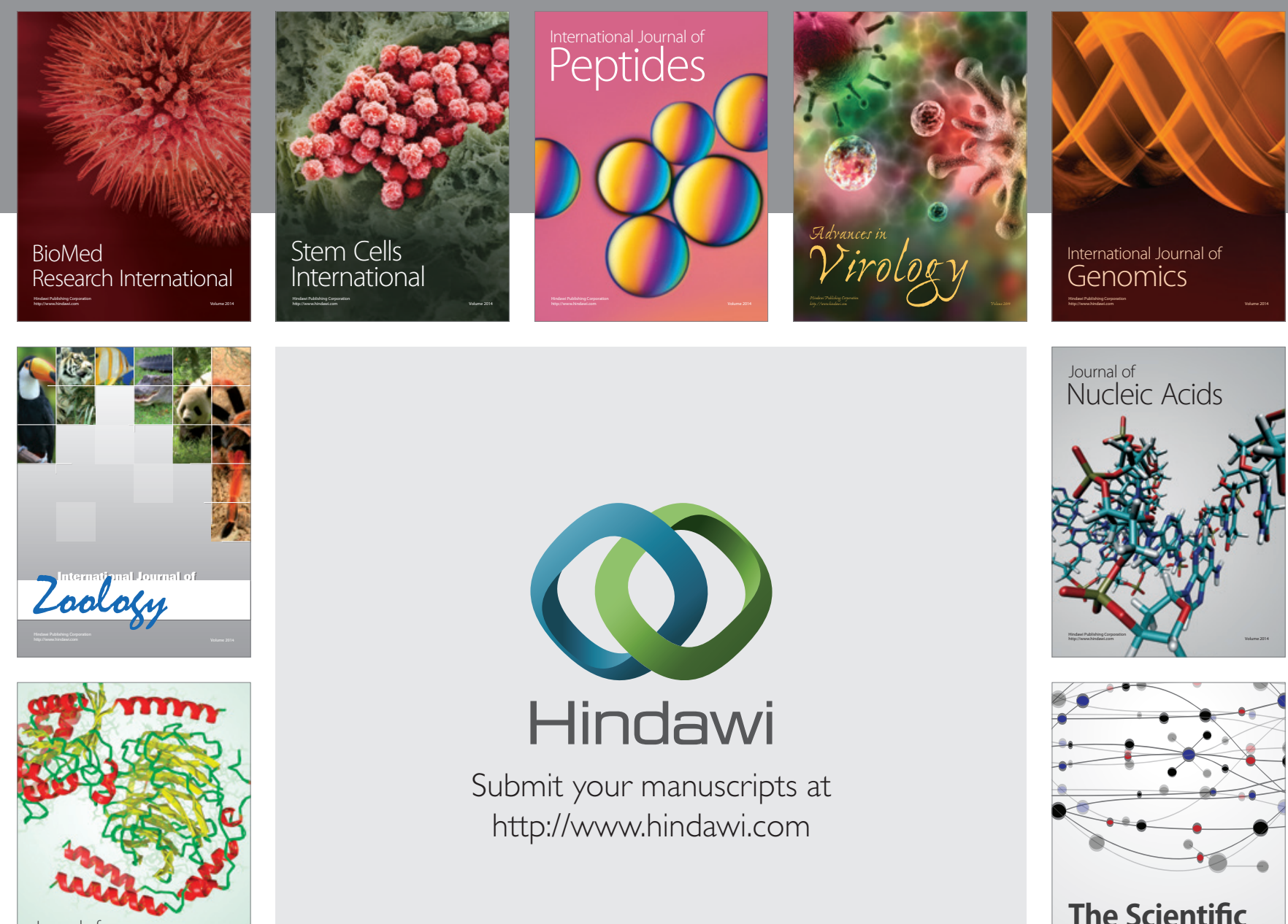

Submit your manuscripts at

http://www.hindawi.com

Journal of
Signal Transduction
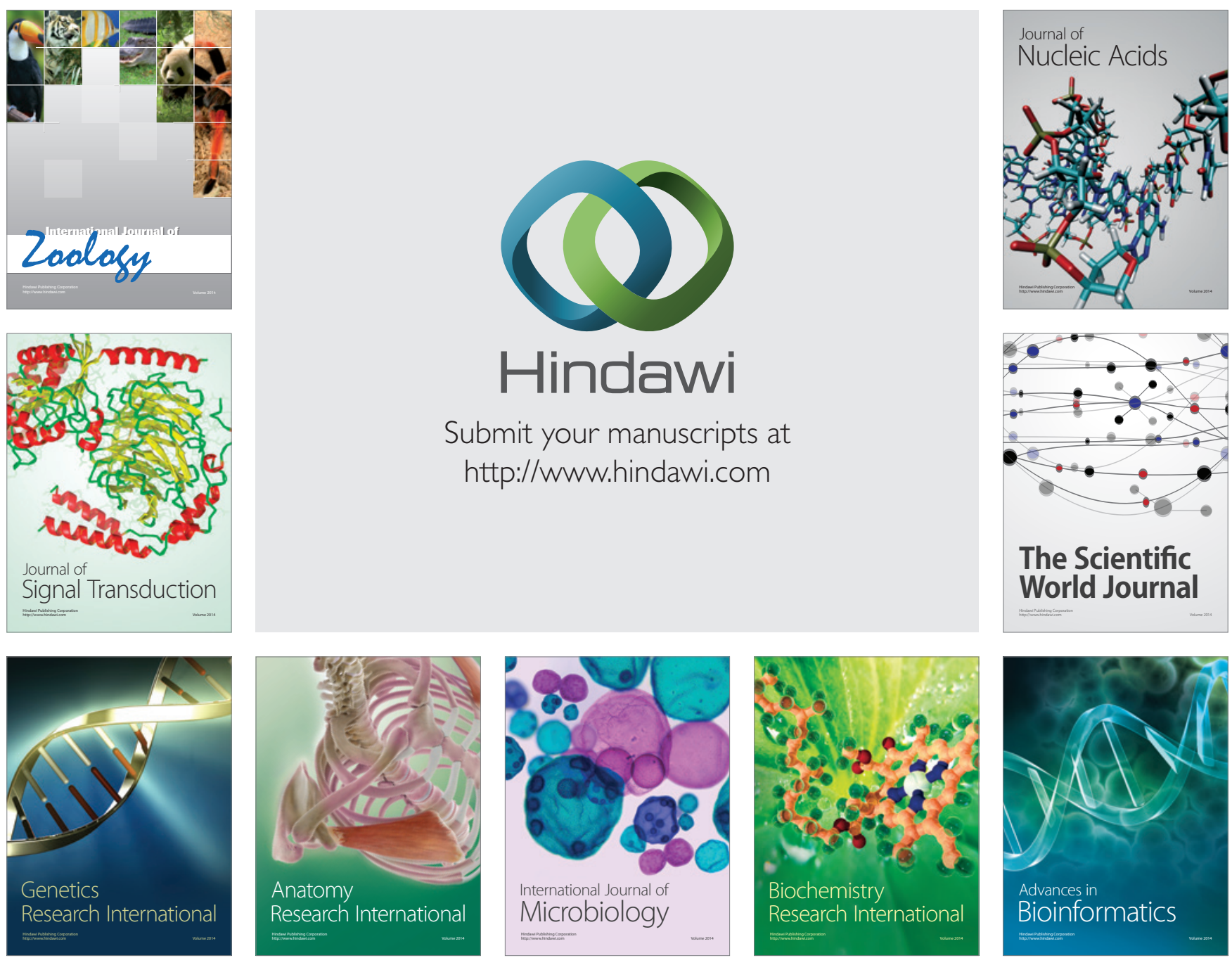

The Scientific World Journal
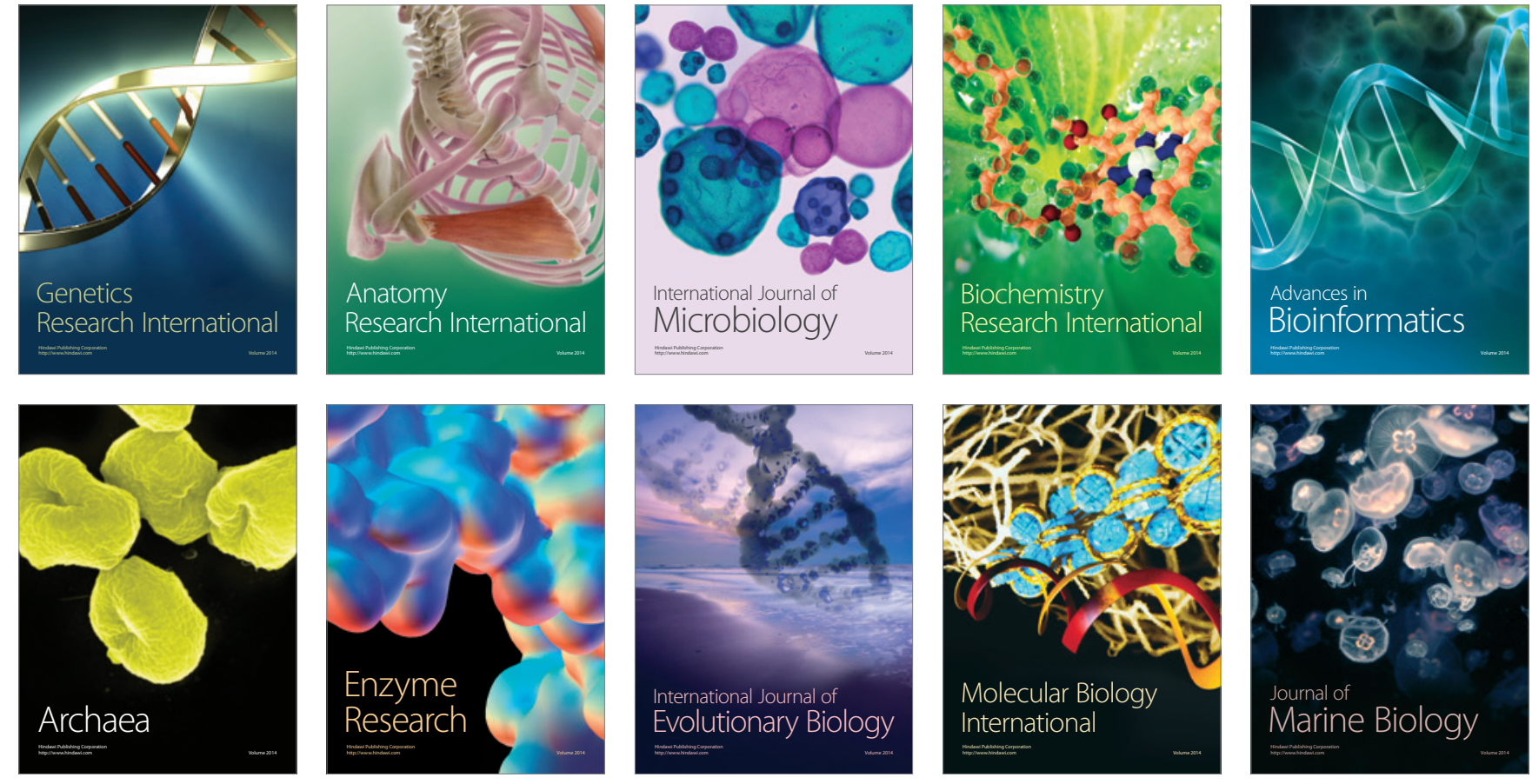